\title{
Safety Investigation of Hazardous Materials Released from the Combined High Temperature Gas Cooled Reactor - Hydrogen Production Plant Using ALOHA Software
}

\author{
D. Priambodo ${ }^{1 *}$, Sunarko ${ }^{1}$, W.W. Purwanto ${ }^{2}$ \\ ${ }^{I}$ Center for Nuclear Energy System Assessment, National Nuclear Energy Agency (BATAN), \\ Jl. Kuningan Barat, Mampang Prapatan, Jakarta 12710, Indonesia \\ ${ }^{2}$ Sustainable Energy Systems and Policy Research Cluster, Department of Chemical Engineering, \\ University of Indonesia, Kampus UI Depok, Jawa Barat 16424, Indonesia
}

\section{ARTICLE INFO}

\section{Article history.}

Received 30 April 2019

Received in revised form 25 November 2020

Accepted 25 December 2020

\section{Keywords:}

Hydrogen

ALOHA

Hazardous material

Toxication

Flammable

Blast

Dispersion

\begin{abstract}
A B S T R A C T
Safety Investigation of Hazardous Materials Released from The Combined High Temperature Gas Cooled Reactor (HTGR) - Hydrogen Production Plant Using ALOHA software has been carried out. Currently, most of studies for HTGRhydrogen plant are focused only on the impact of hydrogen presence to the HTGR plant safety. Therefore, the objective of this study was to investigate the effect of the presence of natural gas and synthetic gas from Steam Methane Reforming hydrogen plant on the combine HTGR-Hydrogen production system using ALOHA software. Three selected hazardous materials: $\mathrm{CH}_{4}, \mathrm{CO}$ and $\mathrm{H}_{2}$ were analyzed. The selected potential hazards of the hazardous materials after leaking from the pipe were downwind suffocation/toxication, flammable area and blast area from vapor cloud explosion. Two types of parameter, i.e., meteorological dispersion (including wind speed, temperature, humidity, nuclear building air changes for day and night) and source release parameters (including pipeline length, and distance from the reactor building to the hydrogen plant), were selected for this study. The effects of the parameters on the hazard distance were then analyzed. The study shows that hydrogen detector needs to be installed at the plant to ensure safety of field operator. Furthermore, $\mathrm{CO}$ adsorber and $\mathrm{H}_{2}$ recombiner should be installed at the Reactor HVAC system for $\mathrm{CO}$ poisoning and $\mathrm{H}_{2}$ fire protection. Provision of a separation distance of more than 250 meters or construction of a blast barrier between the reactor building and the hydrogen plant is also recommended to protect the reactor from $\mathrm{H}_{2}$ explosion hazard.
\end{abstract}

(C) 2021 Atom Indonesia. All rights reserved

\section{INTRODUCTION}

Currently all of urea plants in Indonesia use natural gas both as a feedstock and fuel in the Steam Methane Reforming process for hydrogen production. Some of the plants have begun switching to coal to generate power and steam due to the limitation of natural gas supply. However, the provision of heat for chemical reactor process still uses natural gas. Although natural gas is the cleanest and the most convenient feedstock among the hydrocarbon fuels to produce urea, natural gas is the

\footnotetext{
*Corresponding author.

E-mail address: dedypriambodo@batan.go.id

DOI: https://doi.org/10.17146/aij.2021.939
}

world's fastest growing fossil fuel with consumption increasing from 3,000 MTOE in 2015 to 4,250 MTOE in 2040 [1]. In addition, based on Indonesian natural gas balance 2012 - 2025, Indonesia is facing a declining natural gas production from many older fields and must make substantial investment to maintain current production levels. Therefore, nuclear energy is expected to become a major process heat source for hydrogen production by applying the Steam Methane Reforming process in the future with the necessary modification of chemical reactor design $[2,3]$.

The High Temperature Gas-cooled Reactor (HTGR) is an advanced-generation reactor capable of utilizing high temperature coolant of up to 
$950{ }^{\circ} \mathrm{C}$, which is significantly higher than the $\sim 325{ }^{\circ} \mathrm{C}$ coolant exit temperature with light water reactors (LWRs). The HTGR can be used for high efficiency power production with both a gas-turbine in a direct cycle and/or a superheated steam turbine as a process of heat supply using high temperature helium or steam for a hydrogen production plant or other chemical plants [4-10].

To realize the utilization of nuclear energy, especially HTGR, as a process heat source, the safety design for an integrated HTGR-hydrogen plant should be analyzed. Several studies have been conducted on the safety aspects of nuclear hydrogen systems. US-NRC performed the identification of phenomena relevant to the safety of a nuclear facility when coupled to a hydrogen production plant. A ranking table with criteria for accident phenomena in the coupled system has been established [11]. In addition, possible accident scenarios of the HTGR system plus hydrogen plant based on the sulfur-iodine (S-I) process have been proposed and investigated through qualitative reasoning by Brown et al. [12,13]. Kai Wang investigated the effect of a high pressure hydrogen leak model with multi-parameters to the distribution of hydrogen flammable area [14]. Zhaolin Wang et al. examined the heat and chemical hazard for the integration of nuclear reactors and thermochemical hydrogen plants [15]. Verfondern et al. examined the release, dispersive transport, and explosion of a hydrogen cloud in the atmosphere as well as the release of toxic substances from the JAEA design of an HTGR-S-I hydrogen production plant and their transport towards the NPP control room [16] and Sato $e t$ al. suggested safety requirements and design considerations of such a system [17]. On the other hand, Verfondern and Nishihara investigated particular safety aspects for a combined HTTRSteam Methane Reforming complex such as fire and explosion hazards at the liquid natural gas storage tank, hydrogen storage tank and CO near the HTTR building by using JAERI (today: JAEA) computer tools [18]. Alimah and Sriyono conducted an assessment on the safety distance between nuclear installation and hydrogen storage tank, where they applied the German BMI's empirical formula to determine the minimum separation distance to the hydrogent storage [19].

The literatures above mostly focused on studying the potential hazards arising from the storage systems of either hydrogen or LNG, representing the highest risk of HTGRs because of their huge energy content. The objective of this study was to investigate the impact of natural gas or synthesized gas from a Steam Methane Reformingbased hydrogen plant combined with an HTGR to predict the consequences of such inadvertent release accident scenarios. The so-called Areal Locations of Hazardous Atmospheres (ALOHA) code was utilized to predict the outcome of a hazardous material release from a pipeline carrying natural gas as feed for the reformer and hydrogen, $\mathrm{CO}$ and $\mathrm{CO}_{2}$, as product gases from the reforming process, which are categorized as hazardous materials. Using ALOHA, probable impacts of the evolving flammable and/or toxic gas clouds, thermal radiation zones and overpressure waves can be assessed. In the following section the methodology of the research and the assumed scenarios are introduced, and finally the results are presented. The paper concludes with a discussion of the results, suggestions and conclusions.

\section{THEORY}

\section{Combined HTGR-hydrogen production system based on steam-methane reforming}

The author, in the previous study, describe the Steam Methane Reforming hydrogen production as a process consisting of three stages: steam reforming, shift reaction, and hydrogen product purification as shown in Fig. 1 [2]. The steam reforming process involves methane reacting with medium pressure steam at $750-800{ }^{\circ} \mathrm{C}$ to produce synthesis gas (syngas), a mixture primarily composed of hydrogen $\left(\mathrm{H}_{2}\right)$, carbon dioxide $\left(\mathrm{CO}_{2}\right)$ and carbon monoxide (CO). The steam reforming reaction is endothermic, i.e., heat must be supplied to the process for the reaction to proceed. The process heat required in the primary reformer (PR) is supplied by helium gas from the HTGR via an intermediate heat exchanger (IHX) to a secondary helium circuit. The specifications of the PR and its catalyst have been studied by the authors in the previous study [2]. In addition, the system will be equipped with a secondary reformer (SR). Process gas from the PR is reacted with oxygen in the SR to produce a syngas mixture that is ideal for methanol synthesis or with air to produce ideal syngas for ammonia. The SR is much more compact than the PR. In the SR, combustion of the process gas of hydrocarbon by oxygen causes a temperature rise that provides heat for the secondary reforming reaction. The SR will reduce the remaining methane from $\mathrm{PR}$ then increase the share of $\mathrm{CO} \& \mathrm{CO}_{2}$ in the syngas. In the second step, known as the water gas shift (WGS) reaction, the $\mathrm{CO}$ produced in the first reaction is reacted with steam over a catalyst to form hydrogen and $\mathrm{CO}_{2}$. This process occurs in two stages: the first stage consists of a high temperature shift (HTS) at $350-400{ }^{\circ} \mathrm{C}$ and a low temperature shift (LTS) at $190-250{ }^{\circ} \mathrm{C}$ and the second stage is a purification process to separate the main products of $\mathrm{H} 2$ and $\mathrm{CO} 2$. The modern plant for purification will apply Pressure Swing Adsorber (PSA) for separating $\mathrm{H}_{2}$ from the syngas that can meet purity requirements up to 99.999 mole \% of $\mathrm{H}_{2}$ [20,21]. 


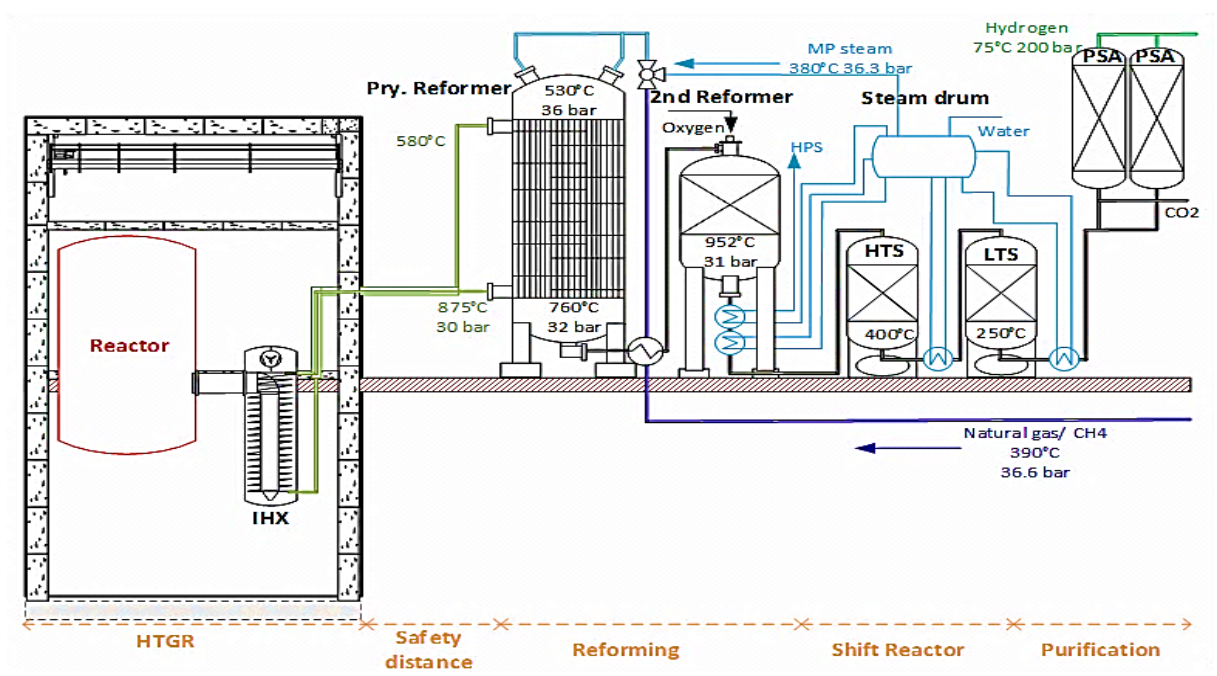

Fig. 1. HTGR-Steam Methane Reforming system for nuclear-assisted hydrogen production [2].

As described in the previous study [2], the HTGR-Steam Methane Reforming plant considered here is designed to produce 150,000 tonnes/year or $5.3 \mathrm{~kg} / \mathrm{s}$ of hydrogen. Correspondingly, the need of natural gas feed to the PR is $15.9 \mathrm{~kg} / \mathrm{s}\left(66.4 \% \mathrm{CH}_{4}\right)$ and $51.6 \mathrm{~kg} / \mathrm{s}$ of Medium Pressure Steam. The heat of the endothermic reaction is $513 \mathrm{MJ} / \mathrm{h} \approx 143 \mathrm{MW}_{\text {th }}$ which is to be supplied by the HTGR. In the SR, syngas is reacted with $7.9 \mathrm{~kg} / \mathrm{s}$ of oxygen. During operation, $75.5 \mathrm{~kg} / \mathrm{s}$ of syngas is formed consisting of $\mathrm{CH}_{4}, \mathrm{H}_{2}, \mathrm{CO}, \mathrm{CO}_{2}, \mathrm{H}_{2} \mathrm{O}$ and $\mathrm{N}_{2}$. A detailed composition of the gas mixture at various positions in the Steam Methane Reforming plant is described in Table 1.

Table 1. Syngas composition [2]

\begin{tabular}{ccr}
\hline Location & Composition & \multicolumn{1}{c}{$\%$} \\
\hline Outlet PR & $\mathrm{CH}_{4}$ & 8.05 \\
& $\mathrm{CO}$ & 10.48 \\
& $\mathrm{CO}_{2}$ & 21.68 \\
& $\mathrm{H}_{2} \mathrm{O}$ & 54.51 \\
& $\mathrm{H}_{2}$ & 5.25 \\
& $\mathrm{~N}_{2}$ & 0.03 \\
\hline Outlet SR & $\mathrm{CH}_{4}$ & 0.54 \\
& $\mathrm{CO}$ & 20.51 \\
& $\mathrm{CO}_{2}$ & 20.14 \\
& $\mathrm{H}_{2} \mathrm{O}$ & 52.89 \\
& $\mathrm{H}_{2}$ & 5.90 \\
& $\mathrm{~N}_{2}$ & 0.02 \\
\hline Outlet HTS & $\mathrm{CH}_{4}$ & 0.54 \\
& $\mathrm{CO}$ & 4.83 \\
& $\mathrm{CO}_{2}$ & 44.78 \\
& $\mathrm{H}_{2} \mathrm{O}$ & 42.80 \\
& $\mathrm{H}_{2}$ & 7.03 \\
& $\mathrm{~N}_{2}$ & 0.02 \\
\hline Outlet LTS & $\mathrm{CH}_{4}$ & 0.54 \\
& $\mathrm{CO}$ & 0.51 \\
& $\mathrm{CO}_{2}$ & 51.57 \\
& $\mathrm{H}_{2} \mathrm{O}$ & 40.02 \\
& $\mathrm{H}_{2}$ & 7.34 \\
& $\mathrm{~N}_{2}$ & 0.02 \\
\hline Purge PSA & $\mathrm{CH}_{4}$ & 0.54 \\
side-product & $\mathrm{CO}$ & 0.51 \\
& $\mathrm{CO}_{2}$ & 51.57 \\
& $\mathrm{H}_{2} \mathrm{O}$ & 0.23 \\
& $\mathrm{H}_{2}$ & 0.37 \\
& $\mathrm{~N}_{2}$ & 0.02 \\
\hline & & \\
& &
\end{tabular}

\section{METHOD}

\section{The areal locations of hazardous atmospheres (ALOHA) code}

The accident scenarios were calculated using ALOHA which was developed by the United States Environmental Protection Agency (U.S. EPA) and the National Oceanic and Atmospheric Administration (NOAA) [22]. The mathematical models used in ALOHA are: Gaussian model, heavy gas dispersion model, vapor cloud explosion model, and BLEVE fireball model. The calculation steps of the outcome of hazardous material release from a gas pipeline within the combined HTGR-Hydrogen production system using ALOHA are shown in Fig. 2 [23].

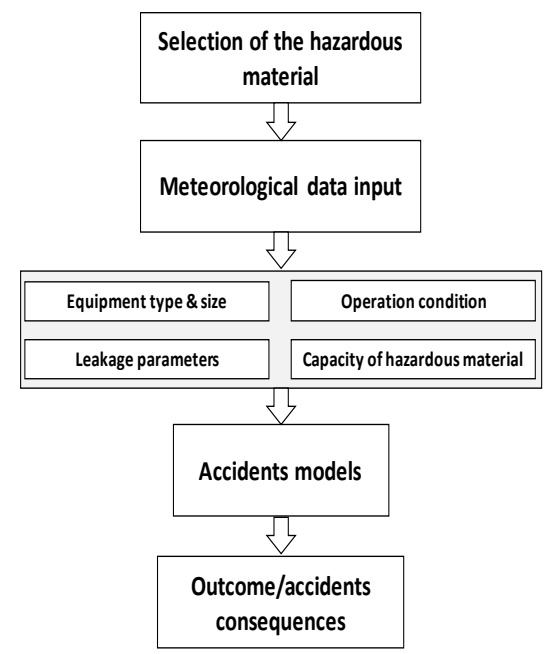

Fig. 2. Calculation steps in ALOHA.

\section{Hazardous material identification}

The hazardous materials were identified by using rating systems for health $(\mathrm{Nh})$, flammability 
(Nf) and reactivity (Nr) from the National Fire Protection Association (NFPA) system and the material factors (MF) [24-26], as shown in Table 2

Table 2. Material safety data sheet [24-26]

\begin{tabular}{cccccc}
\hline No & Material & Nh & Nf & Nr & MF \\
\hline 1 & $\mathrm{He}$ & 0 & 0 & 0 & 1 \\
2 & $\mathrm{CH}_{4}$ & 2 & 4 & 0 & 21 \\
3 & $\mathrm{CO}$ & 3 & 4 & 0 & 21 \\
4 & $\mathrm{CO}_{2}$ & 2 & 0 & 0 & 1 \\
5 & $\mathrm{H}_{2}$ & 0 & 4 & 0 & 21 \\
6 & $\mathrm{H}_{2} \mathrm{O}$ & 0 & 0 & 0 & 1 \\
7 & $\mathrm{~N}_{2}$ & 0 & 0 & 0 & 1 \\
\hline
\end{tabular}

As shown in Table 2, $\mathrm{He}, \mathrm{CO}_{2}, \mathrm{H}_{2} \mathrm{O}$ and $\mathrm{N}_{2}$ are not hazardous materials and are not considered in this study. Through combination of flowrate and material factor, the hazardous chemicals can be sorted to $15.9 \mathrm{~kg} / \mathrm{s}$ of natural gas (feedstock assumed to be $100 \%$ methane) at inlet PR, $15.4 \mathrm{~kg} / \mathrm{s} \mathrm{CO}$ at outlet $\mathrm{SR}$ and $5.3 \mathrm{~kg} / \mathrm{s}$ of $\mathrm{H}_{2}$ (product) at the PSA unit.

\section{Parameters}

To study the accident consequences, release scenarios were developed and calculated. In this study, the model parameters were divided into source release and atmospheric dispersion parameters. The meteorological dispersion parameters include wind speed, temperature, humidity, nuclear building air changes for day and night while the source release parameters include pipeline length, and distance from reactor building to hydrogen plant. Data on the pressures and temperatures of the fluid were taken from the author's previous study, as presented in Fig. 1 [2], and the pipe diameter was derived by trial and error to find the designed flowrate of material.

Table 3. Meteorology [1]

\begin{tabular}{ccccc}
\hline Wind speed $(\mathbf{m} / \mathbf{s})$ & $\begin{array}{c}\text { Temperature } \\
\left({ }^{\circ} \mathbf{C}\right)\end{array}$ & $\begin{array}{c}\text { Humidi } \\
\text { ty }(\%)\end{array}$ & $\begin{array}{c}\text { Cloud } \\
\text { cover }\end{array}$ \\
\hline Day & $2 ; 2.5 ; 3 ; 3.5 ; 4$ & 32 & 70 & Partly \\
Night & $6 ; 6.5 ; 7 ; 7.5 ; 8$ & 26 & 85 & Partly \\
\hline${ }^{1}$ this meteorology parameter only for study & &
\end{tabular}

The assumed pipe length of $1 \mathrm{~km}$ is only applicable to the natural gas to be transferred from the natural gas reservoir compressor to the hydrogen production plant. For the other materials investigated, a 200 meter pipe length was assumed as these gases are transferred between components inside the plant. Air change in the reactor building was assumed to be 2 per hour and the separation distance between reactor building and hydrogen plant is $200 \mathrm{~m}$. In the calculation of the impact from the overpressure wave, the worst-case scenario resulting in a detonation was selected. In addition, the worst-case scenario assumed the wind to blow from the hydrogen plant in the direction of the nuclear plant and the pipeline was totally ruptured. With regard to topography, open country was assumed, i.e., no obstacle to gas dispersion present.

The potential hazards of a hazardous material after leaking from the pipe are downwind suffocation/intoxication and vapor cloud explosion of regions within the flammability limits when ignited after escaping from pipeline, connected with blast overpressures within a certain area.

\section{Hazard levels of concern modelled by ALOHA}

For toxic release accidents, the study uses used public exposure guidelines preferentially for the toxic levels of concern (LOC) because these guidelines are specifically designed to predict how the general public will respond to a short-term, onetime release. The most common public exposure guidelines have three tiers of exposure values for each covered chemical.

The first tier or yellow zone is a mild effects threshold; the second tier or orange zone is an escape-impairment threshold; and the third tier or red zone is a life-threatening effects threshold [22]. With regard to $\mathrm{CO}$, the Acute Exposure Guideline Levels (AEGLs) for zoning the threat of a toxic material are were used while for the other hazardous materials of $\mathrm{CH}_{4}$ and $\mathrm{H}_{2}$, the Protective Action Criteria for Chemicals (PACs) were employed as there are no AEGL values in the ALOHA library for those materials. The AEGL values for $\mathrm{CO}$ were defined as AEGL-3 (red zone-330 ppm $60 \mathrm{~min}$ ) and AEGL-2 (orange zone-83 ppm $60 \mathrm{~min}$ ).

The flammability range of a gas-air mixture is the concentration percentage between the two values of lower explosive limit (LEL) and upper explosive limit (UEL). For the purpose of conservativism, ALOHA uses $60 \%$ and $10 \%$ of LEL as the lower flammability limit of the vapor cloud. If a flammable region of the vapour cloud comes into contact with an ignition source, it will burn fast and forms an overpressure wave.

In this study, the default overpressure wave zone from ALOHA was used which is defined as follows: $8.0 \mathrm{psi}$ (red zone-destruction of building), $3.5 \mathrm{psi}$ (orange zone-serious injury) and $1.0 \mathrm{psi}$ (yellow zone-shatters glass). However, this study considered only the red and orange zones. Since the maximum design pressure of the HTGR containment building has not been designed yet, the design pressure selected here was 180 psi [27]. 


\section{RESULTS AND DISCUSSION}

\section{Affected distance analysis of downwind intoxication}

Figure 3 presents the shape of the toxic threat zones of $\mathrm{H}_{2}, \mathrm{CH}_{4}$ and $\mathrm{CO}$ under two conditions: 1) at day wind speed of $2 \mathrm{~m} / \mathrm{s}$, atmosphere temperature of $32{ }^{\circ} \mathrm{C}$, humidity of $70 \%$ and 2) at night $6 \mathrm{~m} / \mathrm{s}$, $26{ }^{\circ} \mathrm{C}, 85 \%$, and partly cloudy for both conditions. The effects of the wind speed parameters at day and night are shown in Fig. 4. A higher wind speed results in shorter toxic affected distances for both day or night condition. The results for day and night exhibit significant differences for all hazardous materials. The influence of wind speed and day/night conditions on the affected distance can be explained as follows: the wind causes the hazardous gas cloud to disperse in downwind direction while the gas concentration in the vapor cloud is continuously decreasing. This results in a shortening of both the toxic and the flammable vapor cloud extension.
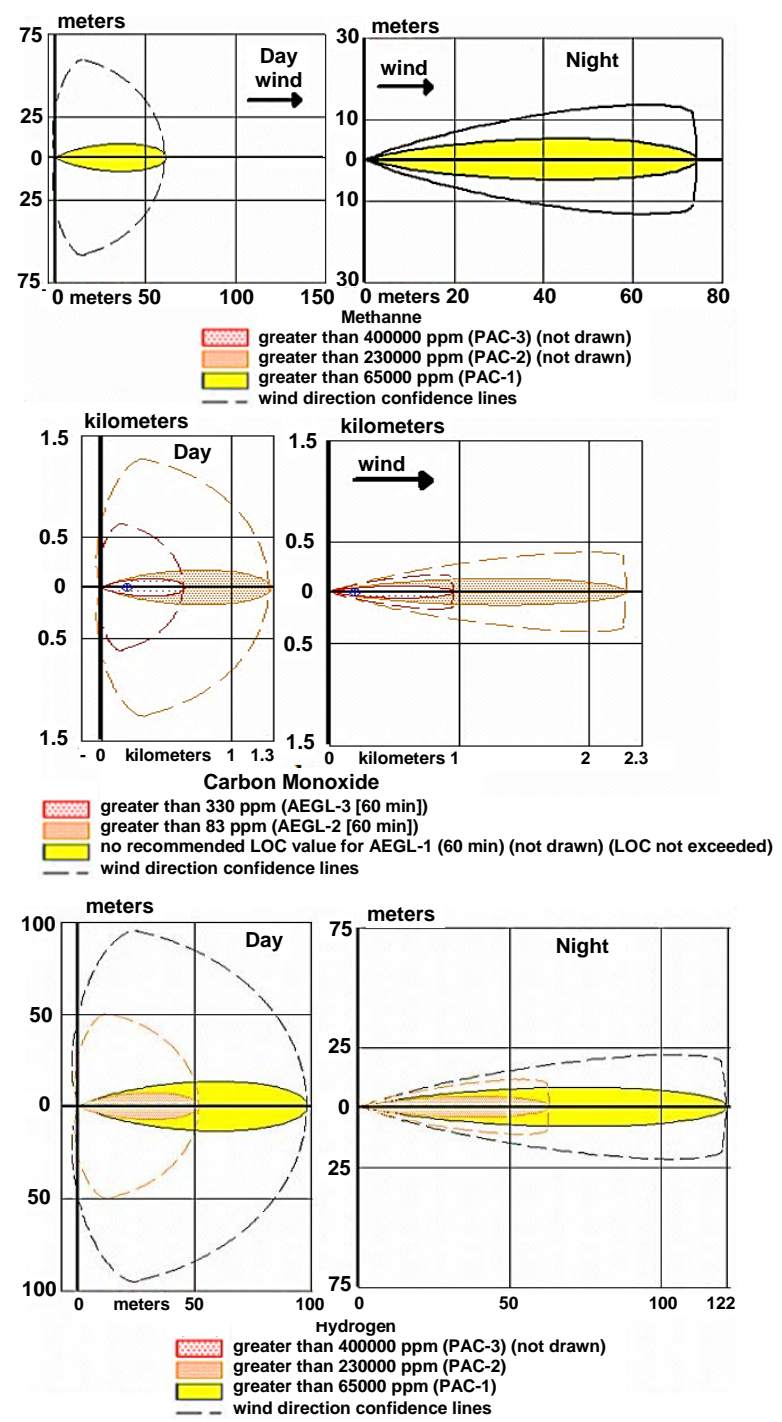

Fig. 3. Threat zone of intoxication for $\mathrm{CH}_{4}, \mathrm{CO}$, and $\mathrm{H}_{2}$ at wind speed: $2 \mathrm{~ms}-1$ for day and $6 \mathrm{~ms}-1$ for night.
The ALOHA modelled the atmospheric conditions for dispersion parameters for day time are classified in Pasquill's atmospheric stability categories of A (highly unstable), B (moderately unstable) and $\mathrm{C}$ (slightly unstable), whereas night time has the categories of D (neutral), E (slightly stable) and F (moderately stable) [28].

For the dispersion parameters at day time, the hazardous gas cloud dilutes faster due to the higher atmospheric turbulence level; hence, the impacted zones does not expand much in the surrounding areas. However, during the night which corresponds to the atmospheric classes of D, E and F, the affected distance expands faster away from the release location. The analysis of the shape of the threat zone and affected distance in relation to the atmospheric stability class shows that, as the conditions change from unstable to stable atmospheric conditions, the affected distance becomes narrower and more extended in wind direction (see Figs. 3, 4 and 5).
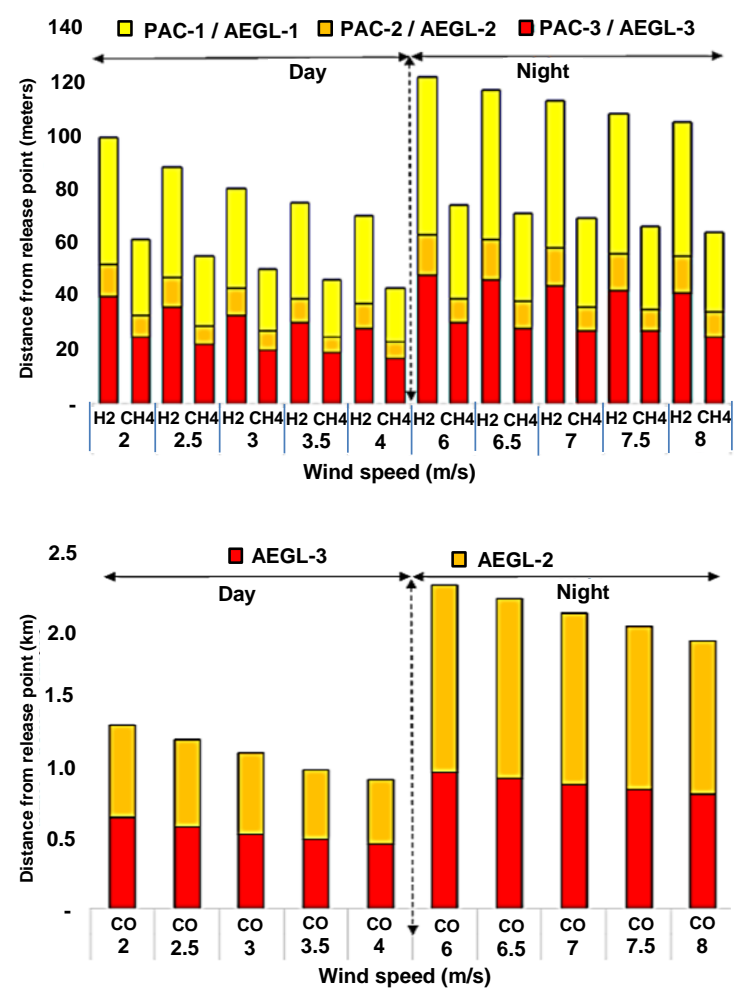

Fig. 4. Affected distance of toxic threat by the hazardous materials $\mathrm{H}_{2}, \mathrm{CH}_{4}$ and $\mathrm{CO}$.

Figure 4 presents the affected distances where $\mathrm{CO}$ has the longest distance followed by $\mathrm{H}_{2}$ while $\mathrm{CH}_{4}$ has the shortest distance under all conditions assumed. This $\mathrm{CO}$ behaviour is due to the fact that it has one of the highest flowrates, a high release rate from the system $\left(\mathrm{CH}_{4}\right.$ is the highest), and it has the smallest LOC value of $330 \mathrm{ppm}$ for red zone compared with 400,000 ppm for $\mathrm{H}_{2}$ and $\mathrm{CH}_{4}$ red zones. Furthermore, $\mathrm{H}_{2}$ has a longer affected 
distance than $\mathrm{CH}_{4}$, even though they have the same LOC values. This phenomenon is due to the effect of $\mathrm{H}_{2}$ density which is lower than that of $\mathrm{CH}_{4}$, $0.0899 \mathrm{~kg} / \mathrm{m}^{3}$ of $\mathrm{H}_{2}$ compared to $0.717 \mathrm{~kg} / \mathrm{m}^{3}$ of $\mathrm{CH}_{4}$. The less dense material will spread more quickly at higher wind speeds. Figure 4 also shows that only $\mathrm{CO}$ could reach the reactor.

\section{Affected distance analysis of flammable area and overpressure}

Figure 5 presents the estimation of affected distances of the flammable vapor cloud and overpressure wave. The trend of both flammable vapor cloud and overpressure wave is similar. Once the flammable vapor cloud reaches an ignition source, this part of the cloud could burn. In some cases, the chemical substance will burn very fast to cause a strong explosion. The strength of the explosion is a function of material, cloud size, type of ignition, and congestion level inside the vapor cloud. The affected distances for $\mathrm{H}_{2}, \mathrm{CH}_{4}$ and $\mathrm{CO}$ on the flammable vapor cloud and overpressure wave show the same trend with $\mathrm{H}_{2}$ having the longest, followed by $\mathrm{CH}_{4}$ and $\mathrm{CO}$. These phenomena are due to the large difference in the values of LEL and UEL of $\mathrm{H}_{2}$ (LEL: $4 \%$ and UEL: $75 \%$ ), then $\mathrm{CH}_{4}$ (LEL: $5 \%$ and UEL: $15 \%$ ) and finally CO (LEL: $12.5 \%$ and UEL: $74.2 \%$ ). The lowest LEL value results in farther affected distance. Figure 5 shows that only $\mathrm{H}_{2}$ flammable area and blast area from $\mathrm{H}_{2}$ explosion could reach the reactor.
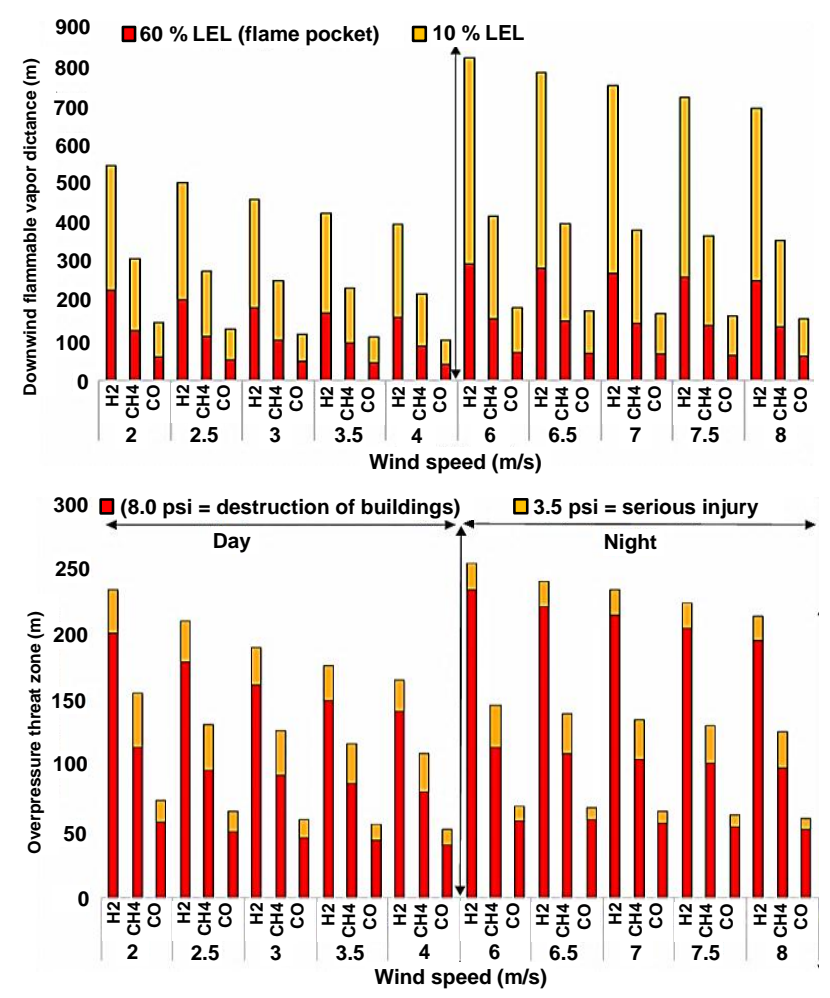

Fig. 5. Affected distance of (a) flammable vapor cloud (b) overpressure wave.

\section{Safety distance analysis for the nuclear- hydrogen plant}

As mentioned in the method section, distance between reactor building and hydrogen plant is $200 \mathrm{~m}$ so that, from the safety distance point of view, the $\mathrm{CO}$, for both day and night conditions, is the only toxication material which could threaten to reach the reactor building. From the assumption of 2 per hour of air change inside the reactor building, ALOHA shows the toxic effect of $\mathrm{CO}$ that reaches the internal reactor building is far above $330 \mathrm{ppm}$ or AEGL-3 toxic level (life-threatening health effects to employee/operator). From ALOHA simulation, the lowest concentration is $1,700 \mathrm{ppm}$ at daytime with a wind speed of $4.0 \mathrm{~m} / \mathrm{s}$ and the highest concentration is $5,430 \mathrm{ppm}$ at night-time with a wind speed of $6.0 \mathrm{~m} / \mathrm{s}$. Therefore, plant protection, i.e., $\mathrm{CO}$ adsorber, should be prepared to protect reactor operator from $\mathrm{CO}$ poisoning.

The case of flammable vapor cloud shows that $\mathrm{H}_{2}$ is the only hazardous material that disperses to the reactor building. There are two conditions at day time and all conditions at night time which result in $60 \%$ LEL (24,000 ppm) inside the reactor building. The concentrations are $31,300 \mathrm{ppm}$ and $25,100 \mathrm{ppm}$ at day time with wind speeds of $2.0 \mathrm{~m} / \mathrm{s}$ and $2.5 \mathrm{~m} / \mathrm{s}$, respectively, while at the night time the highest concentration is $50,000 \mathrm{ppm}$ with a wind speed of $6.0 \mathrm{~m} / \mathrm{s}$ and the lowest concentration is $37,500 \mathrm{ppm}$ with a wind speed of $8.0 \mathrm{~m} / \mathrm{s}$. Thus, on those conditions, the inside of the reactor building is very prone to a fire accident if there were a leak of hydrogen product from the hydrogen plant. Therefore, as the same as $\mathrm{CO}$ poisoning, $\mathrm{H}_{2}$ adsorber/recombiner should be prepared to protect reactor's properties and operator.

As to fire, the explosion threat is also caused only by $\mathrm{H}_{2}$. The highest overpressure wave received by the reactor building is $292 \mathrm{psi}$, occurring at night time when wind speeds are $6-7 \mathrm{~m} / \mathrm{s}$. Compared with the selected containment design pressures, the destructive explosion power of $\mathrm{H}_{2}$ vapor cloud could damage the reactor building. That pressure force threatens not only the reactor building itself but also the operators' life. Under all conditions at day and night time, the overpressure wave from the explosion of the $\mathrm{H}_{2}$-air cloud could seriously injure employees/operators around the reactor building. According to Fig. 5b the maximum destruction distance that could be encompassed by the overpressure wave from the $\mathrm{H}_{2}$ explosion is 250 meter.

\section{CONCLUSION}

The study shows that the affected distances are significantly dependent on the atmospheric 
stability. In addition, the wind speed has a considerable influence on the dispersion of the hazardous material and the extension of the affected distance. The study also shows that the flowrates of the gases and their values of LOC and LEL have a strong effect on the affected distances. Under all conditions, $\mathrm{CO}$ is the only toxic material which could reach the reactor building and give lifethreatening health effects to employees/operators. $\mathrm{H}_{2}$ is the gas that could be threatening the reactor building properties and operators' life. The overpressure force of 292 psi from the $\mathrm{H}_{2}$ explosion could destroy the reactor building and threaten the operators' life. Moreover, from all conditions at day and night time, the overpressure wave from the explosion of the $\mathrm{H}_{2}$-air cloud could seriously injure employees/operators around the reactor building. For protecting operators from $\mathrm{CO}$ poisoning, $\mathrm{CO}$ adsorber equipment could be installed in the heating, ventilation, and air conditioning (HVAC) system of the reactor building so that the $\mathrm{CO}$ concentration in the reactor building could be sufficiently reduced or eliminated during an $\mathrm{CO}$ release accident. The same method could be adopted to reduce $\mathrm{H}_{2}$ flammable gas concentration during a $\mathrm{H}_{2}$ leakage accident by installing $\mathrm{H}_{2}$ recombiner/adsorber in the HVAC system. Provision of a separation distance of more than 250 meter between the HTGR and the hydrogen production system is a simple and reliable safety approach to protect the reactor building from the overpressure wave following a $\mathrm{H}_{2}$ explosion. Another method is to construct a blast barrier between reactor building and hydrogen plant to divert the gas cloud and, in case of an explosion, reduce the pressure force reaching the reactor building.

\section{ACKNOWLEDGMENT}

We thank Dr. Karl Verfonder for his helpful comments that greatly improved the manuscript.

\section{AUTHOR CONTRIBUTION}

Dedy Priambodo contributed as the main contributors of this paper, designed, and performed the models, analyzed the result, and wrote the manuscript in consultation with Sunarko and Widodo W Purwanto. All authors read and approved the final version of the paper.

\section{REFERENCES}

1. Anonymous, World Energy Outlook 2016, IEA (2016).
2. D. Priambodo, E. Dewita and S. Ariyanto, Jurnal Pengembangan Energi Nuklir 14 (2012) 95. (in Indonesian)

3. V. Klimova, V. Pakhaluev and S. Shcheklein, Int. J. Hydrogen Energy 41 (2016) 3320.

4. K. Verfondern and W.V. Lensa, Prog. Nucl. Energy 47 (2005) 472.

5. X. Yan, H. Noguchi, H. Sato et al., Nucl. Eng. Des. 271 (2014) 20.

6. D-H. Shin, C.S. Kim, G-C. Park et al., Int. J. Hydrogen Energy 42 (2017) 22046.

7. M. Al-Zareer, I. Dincer and M.A. Rosen, Energy Convers. Manag. 205 (2020) 112387.

8. R. Pinsky, P. Sabharwall, J. Hartvigsen et al., Prog. Nucl. Energy 123 (2020) 103317.

9. H. Sato, T. Aoki, H. Ohashi et al., Nucl. Eng. Des. 360 (2020) 110493.

10. A. Odukoya, G.F. Naterer, M. Roeb et al., Int. J. Hydrogen Energy (2016).

11. Anonymous, Next Generation Nuclear Plant Phenomena Identification and Ranking Tables (PIRTs) Volume 6: Process Heat and Hydrogen Co-Generation PIRTs, USNRC, Oak Ridge National Laboratory, Oak Ridge, TN 378316170 (2008).

12. N.R. Brown, V. Seker, S.T. Revankar et al., Nucl. Eng. Des. (2012) 256.

13. N.R. Brown and S.T. Revankar, Nucl. Eng. Des. (2012) 266.

14. K. Wang, X. Zhang, Y. Miao et al., Int. J. Hydrogen Energy (2020).

15. Z. Wang, E. Secnik and G.F. Naterer, Process Saf. Environ. Prot. (2015).

16. K. Verfondern, X. Yan, T. Nishihara et al., Int. J. Hydrogen Energy 42 (2017) 7551.

17. H. Sato, H. Ohashi, S. Nakagawa et al., Prog. Nucl. Energy 82 (2015) 46.

18. K. Verfondern and T. Nishihara, Prog. Nucl. Energy 47 (2005) 527.

19. S. Alimah and Sriyono, Jurnal Pengembangan Energi Nuklir 15 (2013) 36. (in Indonesian)

20. E. Herianto, W.R. Wan Daud, S.E.Iyuke et al., Int. J. Hydrogen Energy 34 (2009) 2771.

21. M.R. Rahimpour, M. Ghaemi, S.M. Jokar et al., Chem. Eng. J. 226 (2013) 444.

22. Anonymous, United States Environmental Protection Agency, National Oceanic and Atmospheric Administration (2007). 
23. Y. Zhou, G. Hu, J. Li et al., Land Use Policy 38 (2014) 233.

24. Anonymous, Standard System for the Identification of the Hazards of Materials for Emergency Response, National Fire Protection Association, NFPA 704 (2012).

25. Anonymous, NOAA, US EPA, (n.d.).

26. S. Mannan, Lees' Loss Prevention in the Process Industries: Hazard Identification,
Assessment and Control, $4^{\text {th }}$ Ed., Elsevier Inc. (2012).

27. J.D. Stevenson, SMiRT 19 Conf. Proc. (2007) 1.

28. Z. Comarova and S. Mangul, Simulation and Assessment of Chemical Processes in a Multiphase Environment, in: NATO Science forPeace and Security Series, C, Environmental Security, I. Barnes, M.M. Kharytonov (Eds.), Springer, Dordrecht (2008) 403. 